\title{
L'ús del vídeo en les xarxes socials dels candidats a la Generalitat Valenciana 2019*
}

Carlos López Olano

UNIVERSITAT DE VALÈNCIA

clolanofuuv.es

Sebastián Sánchez Castillo

UNIVERSITAT DE VALÈNCIA

sebastian.sanchez@uv.es

Benjamín Marín Pérez

UNIVERSITAT DE VALÈNCIA

benjamin.marinßuuv.es

Rebut: 08/10/2019

Acceptat: 04/02/2020

RESUM

Els arxius audiovisuals són un recurs cada vegada més emprat en les xarxes socials, també amb finalitat política. Unes xarxes que, enfront dels mitjans tradicionals, sembla que cada vegada tenen més importància, especialment quan es produeixen els moments decisius de les democràcies: les campanyes electorals. En l'estudi volem comprovar si aquest ús ha arribat als comptes personals dels candidats i les candidates a la Generalitat Valenciana en les eleccions d'abril de 2019 i com ho ha fet. Ens fixem especialment en les diferències entre les tres xarxes analitzades -Facebook, Twitter i Instagram - i també quin tipus d'informació de vídeo es comparteix. Per a l'anàlisi, hem creat nou categories formals diferents, algunes de les quals aprofiten recursos provinents dels mitjans tradicionals, d'altres han sigut creades ad hoc per a la difusió per les xarxes. A partir d'aquestes categories, comprovem quines són les més emprades i quines són les pautes de difusió dels candidats. També hi analitzem si hi ha diferències en aquests usos en l'eix dicotòmic de partits d'esquerra/dreta. Els resultats n'apunten un ús discrecional i una inexistent estratègia de comunicació en la utilització dels arxius audiovisuals per part dels candidats.

Paraules clau: xarxes socials, política, eleccions, comunicació audiovisual, Comunitat Valenciana.

*Aquest article està finançat pel Ministeri d'Economia i Competitivitat d'Espanya, i forma part del projecte d'R+D Mediaflows (referència CS02016-77331-C2-1-R). 
ABSTRACT. The use made of video in the social media by candidates in the 2019 Valencian Autonomous Government elections Videos are increasingly being used in social networks for a wide range of purposes, including political campaigning. Here, social media seem to be gaining an edge over traditional ones when it comes to making political choices, especially during election campaigns. This paper examines the extent to which social media is used in Valencian Autonomous Government elections and looks at each of the candidates experiences in this regard in the April 2019 elections. We pay particular attention to the differences between the three networks analysed - Facebook, Twitter and Instagram, and consider what kind of video information is shared. For these purposes, we create nine formal categories, some of which draw on traditional media while others are created ad hoc for our study. Based on these categories, we identify which media are most used, and give guidelines on best practices. We also consider differences in usage between politicians from the left and right ends of the political spectrum. The results point to a general lack of communication strategy in candidates' use of discretionary video materials.

Keywords: social media, politics, elections, audiovisual communication, Comunitat Valenciana.

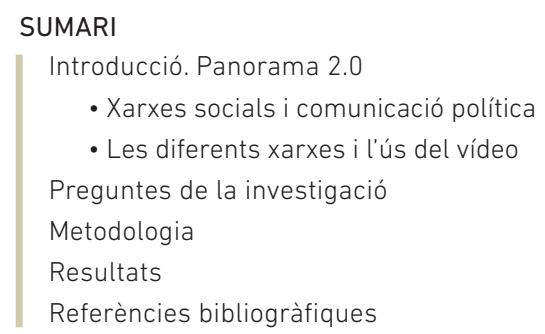

Autor per a correspondència / Corresponding author: Carlos López Olano. Universitat de València, Facultat de Filologia Traducció i Comunicació, Av. Blasco Ibáñez, 32 planta 5a. 46010 València (España).

Citació suggerida / Suggested citation: López-Olano, C. et al. (2020). L'ús del vídeo en les xarxes socials dels candidats a la Generalitat Valenciana 2019. Debats. Revista de cultura, poder i societat, 134(1), 117-132. DOI: http://doi.org/10.28939/iam.debats.134-1.7

\section{INTRODUCCIÓ. PANORAMA 2.0}

«Tot ha canviat, tot és diferent: des que la Galàxia Internet va nàixer amb un origen entre la gran ciència, la investigació militar i la cultura libertària» (Castells, 2001). Des del primer moment, les successives fases de valoració del fenomen que han arribat han alternat entre el pessimisme i l'optimisme dels experts: des de la primera onada, fa més de vint anys, que va fer pensar que es crearia una democràcia virtual, que faria desplaçar l'opinió i l'esfera pública habermasiana cap a l'infinit espai web (Loader i Mercea, 2011), fins a les més actuals i catastrofistes, com la de Benk- ler, Faris i Roberts, que han advertit des de Harvard del moment post-truth (postveritat) en què ens trobem, on creix sense control la desinformació i la propaganda en les influents xarxes (2018). Res de nou en aquestes visions contràries, les dicotomies clàssiques, com les d'Umberto Eco, entre apocalíptics i integrats es repeteixen i es perpetuen també en aquest camp. Eco (1968) ja proposava que el mitjà estrela d'aquella època, la televisió, havia d'ensenyar al públic que no havia de mirar aquest mitjà més enllà del necessari pel seu poder hipnòtic. Habermas (1989: 231) definia aquesta esfera pública com «un domini de la nostra 
vida social en què l'opinió pública pot conformar-se». Per a aquest autor alemany, l'accés a l'esfera pública està obert a tota la ciutadania i una porció se'n constitueix en cada conversa en què individus privats es reuneixen en públic.

Hui les reunions públiques es troben majoritàriament en les xarxes socials. Amb la seua irrupció dins de l'univers d'Internet s'ampliaren les funcions del receptor - ara, usuari-, que va convertir-se en actiu en la web 2.0 (Túñez i Sixto, 2011). L'evolució va arribar a totes les parcel-les informatives, com en l'anomenada política 2.0 (Barberá i Cuesta, 2018) o la ciberdemocràcia (Dader García i Campos, 2006). Algun autor, com Caldevilla Domínguez (2009), defensa el terme democràcia 2.0 i proposa, fins i tot, oblidar la paraula militant i substituir-la per ciberactivista, amb què es defineix la ciutadania interessada a participar activament en política i que es val de diverses eines digitals per a aconseguir-ho (2009). Augmenta la preocupació que la gent jove està perdent interés en la política, però hi ha, en canvi, un «optimisme generalitzat de que les xarxes socials poden estimular la participació política entre la gent jove» (Storsul, 2014: 14). L'arquitectura d'Internet pot ajustar-se molt bé a l'aproximació dels joves cap a l'activitat política, més informal, antiautoritària i orientada a la influència dels parells, dels companys (Livingstone, 2009).

La revolució que han suposat la introducció i l'èxit de les xarxes socials ha provocat simultàniament convergència i col-lisió entre els vells mèdia i els nous (Jenkins, 2006). A més, cal destacar que hem passat de la flow television (televisió lineal) a la file television (Kompare, 2002), no solament amb Youtube sinó també amb la televisió per cable, els serveis de contingut en streaming, com Netflix o $\mathrm{HBO}$, o les versions a la carta de les televisions convencionals (Elorriaga i Monge, 2018). Això sí, cal recordar que la fi de la televisió no ha arribat i que el que trobem és una crisi, tan sols, de la transmissió lineal tradicional dels continguts audiovisuals, especialment entre els joves (Prado, 2013). Altres autors pensen també que la televisió n'és el mitjà principal, encara que cada vegada més allunyada de la seua forma tradicional: els hàbits dels millennials estan marcats per la inclusió de les noves tecnologies i la facilitat d'accés a la informació política (Lago Vázquez, Direito Rebollal, Rodríguez Vázquez i López García, 2016). Aquest canvi en l'emissió/recepció massiva de la informació audiovisual produeix un fenomen comú en els mitjans tradicionals, que augmenten de forma general el volum d'informació subministrat a través de diverses plataformes, tot i la reducció de pressupostos per la crisi. Ara bé, tot això, en qualsevol cas, no vol dir, desgraciadament, que aquesta expansió digital implique més diversitat en el contingut o més pluralisme (Doyle, 2015; López Olano i Fenoll, 2020).

De l'èxit i de la implantació de les diferents xarxes socials - especialment entre els més joves-, en tenim certeses des de fa molt de temps, i cada vegada més sòlides: segons les dades referides a 2018, hi ha 25,5 milions d'usuaris a Espanya, i el 89 \% dels internautes entre 16 i 65 anys té al menys un perfil actiu. A més, una altra dada interessant, el $57 \%$ dels usuaris de les xarxes les utilitzen per a obtenir informació (IAB, 2018).

\section{XARXES SOCIALS I COMUNICACIÓ POLÍTICA}

Una part important d'aquesta informació que arriba per les xarxes socials és de caire polític, l'àmbit en el qual centrarem la nostra investigació. Sense dubte, la campanya que va donar la victòria al president Barack Obama als Estats Units l'any 2008 fou el primer cas pràctic d'aplicació de política online amb èxit (Guterres Ludwig, 2009). Una utilització de les xarxes socials que després tornaria a posar-se en pràctica en la campanya de 2012. La investigació de Baviera, García i Cano Orón (2017) en la campanya de les eleccions generals d'Espanya de 2015, amb un corpus de 900.000 usuaris, mostrà el gran protagonisme dels usuaris de Twitter en la discussió pública $\mathrm{i}$ «una certa hibridació de les diferents lògiques mediàtiques, en especial la televisió i la comunicació audiovisual, així com la dependència de Twitter respecte a la televisió amb certs trets de vicarietat» (p. 190). 
Però un punt d'inflexió important va arribar l'any 2016 amb dues convocatòries electorals, totes dues amb un resultat inesperat, la repercussió de les quals ha provocat un canvi de paradigma en la consideració de la informació política transmesa a través de les xarxes. La primera convocatòria fou la del Brexit, que immediatament va costar el càrrec al primer ministre britànic, David Cameron, i que va engegar una crisi europea i internacional que va provocar l'eixida de Gran Bretanya de la Unió Europea l'1 de febrer de 2020. La segona fou la victòria de Donald Trump en les eleccions presidencials dels Estats Units. El resultat d'aquestes dues cites va originar, segons alguns autors, una «crisi epistèmica en les societats democràtiques contemporànies» (Benkler et al., 2018: 4). Des del referèndum del Brexit i les presidencials dels Estats Units, el tecnopessimisme ha assolit, sense dubte, noves quotes. Altres autors, com ara Rhys Crilley i Marie Gillespie (2019), consideren que el repte més gran al qual han d'enfrontar-se els periodistes hui en dia és el creixement desregulat però continu de les plataformes de social media i les vies associades en què actuen els actors polítics per als seus propis fins. La desconfiança envers els mitjans tradicionals ha sigut, en alguns casos, promocionada pels actors polítics principals: el mateix Trump afirma en les seues memòries el següent: «Ningú és més deshonest que la premsa. Hi ha alguns bons periodistes, però també molts rufians» (2008: 152). Altres factors negatius que contribueixen a la desestabilització política i democràtica que cal tindre en compte en les xarxes són les anomenades echo chambers ${ }^{\mathbf{1}}$ (Benkler et al., 2018) i filter bubble 2 (Pariser, 2011). Alguns asseguren que ens trobem, actualment, en un sistema ecològic de notícies polítiques tòxic pel seu disseny i la falta d'accountability ${ }^{3}$ (Crilley i Gillespie, 2018).

1 Una càmera d'eco, o echo chamber en anglés, provoca que la informació, idees o creences siguen amplificades per transmissió i repetició en un sistema tancat.

2 La bambolla de filtre, o filter bubble, fa que els usuaris d'Internet acaben en una bambolla, allunyats de la informació que no concorda amb els seus punts de vista.

3 El terme accountability fa referència a la responsabilitat de retre comptes.
Tot aquest ambient tens i de desconfiança cap a les xarxes socials també ha arribat a casa nostra, malgrat que els polítics espanyols sembla que no han entés encara la influència que poden tindre en unes eleccions i no han assumit el compromís 2.0, ja que no comprenen les xarxes com un espai de participació sinó com un suport de difusió en què n'hi ha prou amb ser-hi (Túñez i Sixto, 2011). Efectivament, les xarxes es comporten com espais afectius, que generen públics afectius, amb un efecte de sentimentalització i personalització que no convé subestimar (Arias Maldonado, 2016). I tot, perquè un mal ús, un ús que no tinga en compte la idiosincràsia dels diferents social media pot ser contraproduent: el receptor té el control d'allò que vol sentir i no fa cas dels missatges, llevat que tinga la impressió que l'emissor es dirigeix a ell com a individu (Del Moral, 2006). A més, la reacció a un mal missatge pot anar més enllà de la indiferència i convertir-se en un rebuig manifest. Les persones que desitgen influir-hi no només hauran d'estar, a grat o desgrat, en les xarxes socials, sinó que, a més, hauran de mantindre una relació directa i personal amb els destinataris dels missatges (Alcat, 2011). Una altra investigació, la de Valera, Sampietro i Fenoll (2017), posa de manifest la interacció del públic en els perfils de Facebook dels principals partits espanyols (PP, PSOE, Ciudadanos i Podemos) i conclou que són converses democràticament desitjables, perquè la majoria dels usuaris hi intervé seguint unes normes bàsiques de civisme i respecte mutu.

\section{LES DIFERENTS XARXES I L'ÚS DEL VÍDE0}

La recerca de la comunicació política en les xarxes socials és un camp d'estudi i de discussió consolidat, un repte per als investigadors que s'enfronten a un àmbit en continu canvi tecnològic, amb noves eines i aplicacions que es popularitzen i difonen enfront de les ja existents i que incorporen noves possibilitats tècniques (Larsson, 2018 i 2017; Filimonov, Russmann i Svensson, 2016; Lalancette i Raynauld, 2017; Quevedo Redondo i Portalés Oliva, 2017). 
Dins d'aquest panorama general de consideració cap a les xarxes, cal diferenciar i matisar, tant a l'hora d'intentar influir en l'opinió pública com a l'hora de fer-ne una anàlisi. Cada xarxa social té unes pautes de conducta i una forma de comunicació pròpies, i és necessari conéixer-les, comprendre-les i executar-les per traure'n profit (Caldevilla, 2009). Si la comparem amb Facebook, d'ús més familiar, Twitter és la xarxa informativa per excel-lència (Bernal, 2015) i, per tant, és la més lògica, si un candidat vol que els seus missatges polítics arriben als usuaris i tinguen conseqüències en el vot. De fet, tant els partits com els candidats semblen coneixedors dels recursos que els brinda Twitter per a fomentar la interacció amb els seus públics. Encara que són les formacions polítiques les que més exploten aquestes eines, són els tuits que publiquen els candidats els que aconsegueixen una major interacció per part de l'electorat (Miquel Segarra, Alonso Muñoz i Marcos García, 2017). Si parlem de vídeos en Facebook, la categoria basada en menjars i gastronomia és la més habitual, amb més del doble d'interaccions que la següent més vista, la de moda i bellesa (Dent, 2017). La política no sembla important a priori en aquesta xarxa: queda relegada al lloc dotzé. És cert, sense dubte, que en la comunitat creada per Mark Zuckerberg l'any 2004 abunden més els missatges generals que els de matèria política, però la seua penetració és rellevant especialment entre la població més jove, ja que sol ser la primera font que consulten per a obtenir informació (Barberá i Cuesta, 2018).

Segons l'Estudio Anual de Redes Sociales de 2018, respecte a l'accés preferent als diferents tipus, en podem distingir els següents: d'una banda, hi ha l'anomenada Generació $\mathrm{Z}$-els usuaris que tenen entre 16 i 23 anys- que prefereix Instagram; de l'altra, hi ha els millennials — de 24 a 38 anys-que s'inclinen més per Whatsapp i Facebook, als quals dediquen 1,02 hores cada dia, i, finalment, entre els usuaris de 35 a 44 anys, la xarxa més utilitzada és Twitter (31\%), seguida de Facebook (29\%) (IAB, 2018). Tot i que no són les més apropiades per a la comunicació política, menysprear xarxes tan importants entre els joves com Instagram i Facebook no sembla una bona estratègia per a véncer en les eleccions. A pesar del creixement del nombre d'usuaris d'Instagram al món -1.000 milions en juny de $2019-$, resulta cridaner el poc nombre d'investigacions sobre la utilització en comunicació política d'aquesta eina per part de partits i polítics, especialment en comparació amb l'abundant producció que n'hi ha en l'ús de Facebook o Twitter (López García, 2016). No obstant això, en la política internacional l'ús d'Instagram s'ha consolidat com un referent en la captació de l'atenció social, especialment la dels més joves. És el cas de Suècia (Filimonov et al., 2016), del Canadà (Lalancette i Raynauld, 2017), dels Estats Units (Muñoz i Towner, 2017), d'Àustria (Liebhart i Bernhardt, 2017) i d'Espanya (López Rabadán i Doménech Fabregat, 2018; Quevedo Redondo i Portalés Oliva, 2017; Selva Ruiz i Caro Castaño, 2017; Sampietro i Sánchez Castillo, 2020).

Si hi ha una xarxa en la qual el vídeo és important, aquesta és Youtube, sense dubte. Nascuda per a discriminar tot el que no siga missatge audiovisual, encara que hui en dia l'audiovisual contamina i pren rellevància en totes les xarxes. Cal recordar que és el segon lloc web més popular, per darrere només de Google. Hi proliferen els videoblogs o vlogs: vídeos curts en línia, que normalment es filmen a casa, i sovint tenen la forma visual simple d'un monòleg individual dirigit a la càmera (Raby, Caron, Théwissen LeBlanc, Prioletta i Mitchell, 2018). Tot i l'aparent amateurisme i l'estètica no professional que ha creat de manera pràctica un gènere específic, han sorgit algunes agències de talents en mitjans socials, com Gleam Futures, que gestionen i guien les carreres de personalitats carismàtiques que han construït audiències importants en la xarxa (Cocker i Cronin, 2017). I és que, tot $i$ que alguns youtubers, com el suec PewDiePie, ${ }^{4}$ arriben als 60 milions de seguidors i ingressen més de 12 milions de dòlars anuals, molts encara segueixen cultivant una certa estètica amateur i un estil confessional i proper en els seus continguts. Els enquadres són, moltes vegades, poc ortodoxos i hereus de la cultura visual del selfie, que —recordem- fou escollida

4 https://pewdiepie.com [consulta: 20/06/2019] 
paraula de l'any el 2013 per l'Oxford Dictionary. L'èxit del fenomen ha fet que, fins i tot, hi haja oferta acadèmica per $a$ aprendre $a$ triomfar en el gènere, un aprenentatge segurament condemnat a fracassar, atesa la falta de pautes regulars (Elorriaga i Monge, 2018). Els youtubers són percebuts pels joves seguidors com els seus iguals — i això segurament contribueix al seu èxit-, encara que també tenen qualitats que solen admirar: creativitat i talent. Són persones properes, cosa que facilita la ràpida identificació (Pérez Torres, Pastor Ruiz y Abarrou Ben Boubaker, 2018). L'estètica dels vlogs és hereva de la utilització de la càmera web i la celebració de les característiques de les anomenades bedroom cultures (Scolari i Fraticelli, 2017). Exerciten de manera notable les funcions clàssiques del llenguatge: la fàtica —mirar a la càmera constantment dirigint-se a l'espectador- i l'emotiva -també relacionada amb qui rep el missatge. Cadascun dels protagonistes desenvolupa una marca, unes característiques enunciatives pròpies: una salutació, un gest, una forma de parlar concreta i fàcil de reconéixer. Amb totes aquestes característiques i circumstàncies pròpies, Youtube i altres servidors de vídeo en línia, durant la temporada d'eleccions, han fet palesa l'habilitat de mostrar-se com un canal de comunicació política viable (May, 2010). A més, els seus trets estilístics van més enllà del canal pel qual arriben i contaminen qualsevol missatge audiovisual llançat a les xarxes. La influència d'aquest tipus de missatges, sense dubte, cal tindre-la en consideració, sobretot si tenim en compte que, en general, la publicació de vídeos a través d'Internet és molt més econòmica que a través dels mitjans tradicionals (Caldevilla, 2009).

D'altra banda, els partits polítics troben que els perfils personals dels polítics en les xarxes augmenten la vinculació dels votants independents (Bennett, 2012). Això sí, Quevedo Redondo i Portalés Oliva (2017) analitzaren els candidats a la presidència del Govern d'Espanya en les eleccions de 2015 a través dels seus perfils en Instagram durant tot un any i el resultat va ser que la utilització del vídeo $(2,7 \%)$ era residual respecte a la imatge, malgrat la importància del factor audiovisual en l'impacte sobre l'electorat. L'estudi mostrava que les opinions i afirmacions de tipus personal amb alta càrrega d'emotivitat sextuplicaven la petició explícita del vot. Quedava patent una estratègia de persuasió orientada al political fandom en la línia de buscar empatia i proximitat amb els electors perquè els candidats siguen percebuts com a ciutadans amb aptituds per al govern. Així queda ara la participatory culture que anunciava Henry Jenkins (2006, 2017), encara que els usuaris no siguen finalment tan participatius com es pensava.

\section{PREGUNTES DE LA INVESTIGACIÓ}

Davant d'aquesta tessitura, plantegem estudiar, dins del camp de les xarxes socials, l'activitat dels candidats i candidates a la presidència de la Generalitat Valenciana durant la campanya de les eleccions de 2019. I dins del marc general dels posts compartits pels candidats, hem centrat l'anàlisi en els continguts amb un suport audiovisual, de vídeo en diverses formes. L'objectiu de la investigació és aclarir si aquests recursos — cada vegada més importants i comuns-s'hi utilitzen habitualment, i com i de quina manera els fan servir els candidats en un estudi comparatiu. Així, hem plantejat les següents preguntes d'investigació:

RQ1. Quina és la utilització del recurs audiovisual en les diferents xarxes socials per part de les distintes candidatures? Podem trobar diferències en aquesta utilització segons la dicotomia partits d'esquerra/dreta?

RQ2. Hi ha diferenciació en l'ús de la pròpia imatge del candidat o candidata entre els diferents perfils analitzats?

RQ3. Existeix diferenciació formal i narrativa en les propostes audiovisuals segons l'espectre polític de representació?

\section{METODOLOGIA}

S'han considerat 579 unitats d'anàlisi $(\mathrm{n}=579)$, vídeos i píndoles audiovisuals procedents de les xarxes socials públiques de les sis candidatures a la 
Generalitat Valenciana en les eleccions del 28 abril de 2019. S'han tingut en compte tant els continguts de vídeo generats pel mateix perfil com els compartits provinents d'altres fonts o perfils. L'espai temporal analitzat comprén del 12 d'abril al 26 d'abril de 2019, dates en les quals se centra la campanya autonòmica i s'incrementa l'activitat en les xarxes socials. Els polítics proposats per a l'estudi $(\mathrm{M}=3,57$, $\mathrm{DT}=1,62)$ són Ximo Puig del PSPV-PSOE $(\mathrm{n}=82$; $14,2 \%)$, Isabel Bonig del Partit Popular ( $\mathrm{n}=92$; $15,9 \%)$, Mónica Oltra de Compromís ( $\mathrm{n}=120$; 20,7 \%), Rubén Martínez Dalmau de Unides PodemEUPV ( $\mathrm{n}=38 ; 6,6 \%$ ), Toni Cantó de Ciudadanos (n = 193; 33,3 \%) i José María Llanos de Vox $(\mathrm{n}=54 ; 9,3 \%)$. Les 579 propostes audiovisuals procedeixen de Twitter ( $n=414 ; 71,5 \%)$, Facebook $(n=126$; $21,8 \%)$ i Instagram $(\mathrm{n}=39 ; 6,7 \%)$.

Mitjançant una variable dicotòmica s'indica l'espectre polític de les candidatures analitzades, és a dir, dreta (n $=339 ; 58,5 \%)$ i esquerra $(\mathrm{n}=240 ; 41,5 \%)$. També s'ha considerat important quantificar quan la imatge de la persona candidata apareix en el relat audiovisual $(\mathrm{n}=$ $397 ; 68,6 \%)$ i quan no hi apareix ( $\mathrm{n}=182 ; 31,4 \%)$.

Finalment, per construir les variables associades a les unitats d'anàlisi de les categories narratives dels relats audiovisuals, s'ha emprat un procediment mixt deductiu i inductiu. En un primer moment, s'han creat les variables basades en l'experiència acadèmica i professional dels autors de la recerca. Posteriorment, $\mathrm{s}^{\prime}$ ha integrat la fitxa d'anàlisi amb aquestes primeres variables a un $20 \%$ de la mostra, per a la qual cosa s'han rebutjat variables no pertinents i s'han inclòs d'altres que no s'havien considerat al principi. Al final del procés s'han obtingut 9 categories audiovisuals $(\mathrm{M}=4,02, \mathrm{DT}=2,17)$, que són aquestes:

1. Total o tall de veu gravat amb càmera ENG autònoma, com els convencionals destinats a utilitzar-se en informatius de televisió ( $\mathrm{n}=40$; $6,9 \%)$.

2. Tall de veu extret de míting ( $\mathrm{n}=121 ; 20,9 \%)$.

3. Tall procedent d'entrevista o debat en mitjans radiotelevisius ( $\mathrm{n}=196 ; 33,9 \%)$.
4. Notícia d'informatiu o peça o vídeo usual en informatius de televisió ( $\mathrm{n}=4 ; 0,7 \%)$.

5. Emissió en directe de mítings o esdeveniments ( $\mathrm{n}=11 ; 1,9 \%)$.

6. Espot, amb presència de música no diegètica $i$ rètols, no subtítols ( $\mathrm{n}=112 ; 19,3 \%)$.

7. Ambient i recursos sense editar $(n=59 ; 10,2 \%)$

8. Selfie amb estil de youtuber que mira a càmera i interpel-la l'usuari ( $\mathrm{n}=23 ; 4 \%)$.

9. Altres propostes audiovisuals poc comunes o difícils de classificar (tipus llistes d'Spotify i d'altres) ( $\mathrm{n}=13 ; 2,2 \%)$.

El tractament estadístic, que consistia en taules de contingència, anàlisis bivariades i models lineals, s'ha realitzat mitjançant SPSS IBM v.21. Les dades numèriques i percentuals que componen les taules de contingència incloses en la investigació s'han extret després de l'anàlisi del llibre de codis. S'hi ha establit un índex de correlació amb el model khi quadrat $\left(\mathrm{X}^{2}\right)$ per detectar tant les hipòtesis nul.les (Ho) com les hipòtesis alternes $(\mathrm{Ha})$, admetent un nivell de significació, $\alpha=0,05$ (p-valor) dins dels paràmetres establits en les investigacions en ciències socials. En la majoria de les taules incloses, el p-valor associat a l'estadístic khi quadrat és 0,000 altament significatiu. Per tal de confirmar les dades obtingudes mitjançant khi quadrat, s'ha considerat convenient incloure-hi també la mesura simètrica nominal per nominal mitjançant el coeficient Phi, que adopta valors entre 0 i 1 , i el seu valor és idèntic al del coeficient de correlació de Pearson $\left(\mathrm{r}_{\mathrm{x}-\mathrm{y}}\right)$.

\section{RESULTATS}

Després de realitzar el model estadístic, s'han obtingut els primers resultats. Respecte a la RQ1, en la Taula 1 és possible veure el percentatge en l'ús de recursos audiovisuals respecte a la totalitat dels posts publicats en les tres xarxes socials, i fer una primera aproximació sobre l'ús dels vídeos que han fet els candidats en les campanyes de les eleccions autonòmiques. S'hi descobreix que cada partit té una clara preferència per una xarxa social determinada. En 
Taula 1 Candidatura/Ús dels vídeos en xarxes socials

\begin{tabular}{|c|c|c|c|c|c|c|c|c|c|}
\hline & \multicolumn{3}{|c|}{ FACEBOOK } & \multicolumn{3}{|c|}{ TWITTER } & \multicolumn{3}{|c|}{ INSTAGRAM } \\
\hline & Total & Vídeos & $\%$ & Total & Vídeos & $\%$ & Total & Vídeos & $\%$ \\
\hline Toni Cantó & 516 & 19 & 3,6 & 746 & 173 & 22,6 & 8 & 1 & 12,5 \\
\hline Mónica Oltra & 1.515 & 23 & 1,5 & 502 & 82 & 16,3 & 26 & 15 & 57,7 \\
\hline Isabel Bonig & 738 & 36 & 4,8 & 88 & 43 & 48,8 & 26 & 13 & 50 \\
\hline Ximo Puig & 496 & 26 & 5,2 & 161 & 49 & 30,4 & 28 & 7 & 25 \\
\hline José María Llanos & 903 & 2 & 0,2 & 153 & 52 & 33,9 & 2 & 0 & 0 \\
\hline Rubén Martínez & 424 & 20 & 4,7 & 161 & 15 & 9,3 & 13 & 3 & 23 \\
\hline
\end{tabular}

termes quantitatius, tots els candidats a excepció de Toni Cantó han apostat per l'ús de Facebook de forma majoritària. El líder de Ciudadanos ha utilitzat de forma preferent Twitter, xarxa en la qual es mostra molt actiu. Instagram ha estat molt poc considerada en les estratègies de campanya dels candidats, amb tot just 39 vídeos entre totes les candidatures.

La Taula 2 mostra una relació de contingència en la qual és possible observar, en primer lloc, que la xarxa social més emprada en la comunicació de missatges audiovisuals dels grups polítics valencians durant la campanya de les eleccions autonòmiques de 2019 ha sigut Twitter, seguit de Facebook i, en últim lloc, Instagram. També es descobreix que el candidat més actiu en les xarxes analitzades ha sigut, amb diferència, Toni Cantó, seguit de la cap de llista per Compromís, Mónica Oltra. Els altres candidats han resultat ser sensiblement menys actius en les xarxes. Entre les dades obtingudes, destaca el poc ús que el líder d'Unides Podem-EUPV ha fet dels continguts audiovisuals en les xarxes socials durant el període de campanya.

Respecte a la pregunta secundària de la RQ1, és a dir, si podem trobar diferències segons l'eix esquerra/ dreta, en la Taula 3 es mostra l'ús de les xarxes socials segons l'espectre polític dels partits candidats. Encara que amb un lleuger avantatge, l'espectre conservador, PP, Cs i Vox, han resultat ser els partits que
Taula 2 Candidatura/Xarxa social

\begin{tabular}{|c|c|c|c|c|}
\hline & Instagram & Twitter & Facebook & Total \\
\hline $\begin{array}{l}\text { Toni } \\
\text { Cantó }\end{array}$ & $1(0,2)$ & $173(29,9)$ & $19(3,3)$ & 193 \\
\hline $\begin{array}{l}\text { Mónica } \\
\text { Oltra }\end{array}$ & $15(2,6)$ & $82(14,2)$ & $23(4,0)$ & 120 \\
\hline $\begin{array}{l}\text { Isabel } \\
\text { Bonig }\end{array}$ & $13(2,2)$ & $43(7,4)$ & $36(6,2)$ & 92 \\
\hline $\begin{array}{l}\text { Ximo } \\
\text { Puig }\end{array}$ & $7(1,2)$ & $49(8,5)$ & $26(4,5)$ & 82 \\
\hline $\begin{array}{l}\text { José } \\
\text { María } \\
\text { Llanos }\end{array}$ & 0 & $52(9,0)$ & $2(0,3)$ & 54 \\
\hline $\begin{array}{l}\text { Rubén } \\
\text { Martínez }\end{array}$ & $3(0,5)$ & $15(2,6)$ & $20(3,5)$ & 38 \\
\hline Total & 39 & 414 & 126 & 579 \\
\hline
\end{tabular}

$N(\%)$

$X^{2}(10)=111,365^{a}, p<, 000$

2 caselles $(11,1 \%)$ han esperat un recompte menor que 5 .

El recompte mínim esperat és $2,56^{\mathrm{a}}$.

Mesura simètrica nominal per nominal, Phi 439

Font: Elaboració pròpia.

més contingut audiovisual han implementat en les xarxes socials ( $\mathrm{n}=339 ; 58,54 \%$ ), mentre que l'esquerra, PSPV-PSOE, Unides Podem-EUPV i Compromís n'han utilitzant menys. ( $\mathrm{n}=240 ; 41,45 \%)$. 
Taula 3 Espectre polític/Xarxa social

\begin{tabular}{|l|l|l|l|l|}
\multicolumn{1}{|c|}{ Instagram } & \multicolumn{1}{c|}{ Twitter } & \multicolumn{2}{c|}{ Facebook } & Total \\
\hline Dreta & $14(2,4)$ & $\begin{array}{l}268 \\
(46,3)\end{array}$ & $57(9,8)$ & 339 \\
\hline Esquerra & $25(4,3)$ & $\begin{array}{l}146 \\
(25,2)\end{array}$ & $69(11,9)$ & 240 \\
\hline
\end{tabular}

$\mathrm{N}(\%)$

$X^{2}(2)=23,970^{\mathrm{a}}, \mathrm{p}<, 000$.

0 caselles $(00,0 \%)$ han esperat un recompte menor que 5 . El recompte mínim esperat és $16,17^{\text {a }}$.

Mesura simètrica nominal per nominal, Phi .203

Font: Elaboració pròpia.

Taula 4 Candidatura/Presència de la persona candidata en el vídeo

\begin{tabular}{|c|c|c|c|}
\hline & Presència & No presència & Total \\
\hline Toni Cantó & $102(52,8)$ & $91(47,2)$ & 193 \\
\hline Mónica Oltra & $98(81,6)$ & $22(18,3)$ & 120 \\
\hline Isabel Bonig & $85(92,3)$ & $7(7,6)$ & 92 \\
\hline Ximo Puig & $79(96,3)$ & $3(3,6)$ & 82 \\
\hline $\begin{array}{l}\text { José María } \\
\text { Llanos }\end{array}$ & $6(11,1)$ & $48(88,8)$ & 54 \\
\hline Rubén Martínez & $27(63,1)$ & $11(36,8)$ & 38 \\
\hline
\end{tabular}

$\mathrm{N}(\%)$

$X^{2}(5)=168,072^{\mathrm{a}}, \mathrm{p}<, 000$.

0 caselles $(0,0 \%)$ han esperat un recompte menor que 5 .

El recompte mínim esperat és $11,94^{a}$

Mesura simètrica nominal per nominal, Phi .539

Font: Elaboració pròpia.

Quant a la RQ2, referida a l'ús de la pròpia imatge del candidat, en la Taula 4 es mostra el percentatge d'aparició en les propostes audiovisuals implementades en les diferents xarxes socials. Tant Puig com Bonig assumeixen un gran protagonisme en els vídeos que comparteixen: de fet, apareixen en més del $90 \%$ dels vídeos. Oltra queda, tan sols, un poc per baix, però també té una presència molt majoritària (81,6 \%). En canvi, tant Cantó (52,8 \%) com Martínez $(63,1 \%)$ queden més equilibrats, tot i que el nombre d'aparicions de Cantó és el més alt de tots els candidats, ja que la seua activitat en les xarxes és també molt superior. Llanos té una presència residual en el conjunt dels vídeos, una dada que, en qualsevol cas, és poc indicativa per la pobra quantitat de casos.

La seua aparició en les propostes audiovisuals com a actors principals ha resultat ser diferent segons les narratives emprades. En la Taula 5, els talls de veu procedents dels mitjans tradicionals és la narrativa en la qual apareixen els candidats amb major freqüència, situació que es considera òbvia per l'actuació directa de l'actor en els recursos recuperats.

Taula 5 Categoria audiovisual/Presència de la persona candidata en el vídeo

\begin{tabular}{|l|l|l|l|}
\multicolumn{1}{c|}{} & \multicolumn{2}{c|}{ Presència } & \multicolumn{2}{c|}{ No presència } & Total \\
\hline 3.- Tall mitjans & $154(26,6)$ & $42(7,3)$ & 196 \\
\hline 2.- Tall míting & $86(14,9)$ & $35(6,0)$ & 121 \\
\hline 6.- Espot & $67(11,6)$ & $45(7,8)$ & 112 \\
\hline 7.- Ambient & $20(3,5)$ & $39(6,7)$ & 59 \\
\hline 1.- Total & $39(6,7)$ & $1(0,2)$ & 40 \\
\hline 8.- Selfie & $14(2,4)$ & $9(1,6)$ & 23 \\
\hline 9.- Altres & $7(1,2)$ & $6(1,0)$ & 13 \\
\hline 5.- Emissió directe & $9(1,6)$ & $2(0,3)$ & 11 \\
\hline 4.- Notícia inf. & $1(0,2)$ & $3(0,5)$ & 4 \\
\hline
\end{tabular}

$\mathrm{N}(\%)$

$X^{2}(8)=680,226^{a}, p<, 000$.

4 caselles $(22,2 \%)$ han esperat un recompte menor que 5 .

El recompte mínim esperat és $1,26^{\text {a }}$

Mesura simètrica nominal per nominal, Phi .334

Font: Elaboració pròpia.

Respecte a la RQ3, hi ha una diferència molt destacada en l'ús de les narratives audiovisuals per part de les diferents candidatures a la Generalitat Valenciana. En primer lloc, segons les dades observades en la Taula 6, es descobreix que la categoria més emprada en termes generals és la 3 , aquella que es deriva de la reutilització dels talls de veu emesos pels mitjans tradicionals (televisió i ràdio). En segon lloc, apareix la 2, «Talls de veu extrets dels mítings»; i en tercer lloc, la 6 , «Espots gravats 
i editats» —usualment pels mateixos partits—amb finalitats polítiques concretes. També la 5, és a dir, les diverses possibilitats d'emissió en directe dels diferents actes i mítings desenvolupats durant la campanya s'utilitzen, encara que de manera dispar: sobretot és un recurs molt emprat pel candidat socialista. Crida l'atenció aquest ús massiu de peces de contingut audiovisual que provenen de la televisió convencional, ja que no és un producte exclusiu de les xarxes, sinó que s'aprofita que existeix i es difon per aquest mitjà. No ens referim a la categoria 4, que serien directament notícies, vídeos televisius - molt poc emprats-, sinó a la 3 , talls extrets d'entrevistes i debats.

En l'altre extrem, i més propis de la idiosincràsia de la web 2.0, trobem, en primer lloc, categories com la 7, «Ambients i recursos sense editar». Es tracta d'arxius en format RAW, en moltes ocasions clarament amateurs i que han fet militants o seguidors dels actes, però que connecten molt bé amb aquesta afectivitat característica de les xarxes socials, que estableixen, a més, una relació com a parell amb el receptor. En aquesta categoria, clarament, és el candidat de Vox, José María Llanos ( $n=27)$, qui en comparteix més contingut, seguit per Mónica Oltra $(n=17)$ i el cap de llista de Ciudadanos, Toni Cantó $(\mathrm{n}=14)$, tal com podem veure en la Taula 6 . També cal distingir que majoritàriament els posts compartits per Llanos són retuits que mostren el pretés èxit d'afluència d'acòlits als mítings del nou partit per tot Espanya, en molts casos, dels que fa el líder nacional, Santiago Abascal. Ni Puig ni Martínez han compartit cap d'aquests continguts. En segon lloc, també seria propi de les xarxes un tipus de contingut que considerem destacat $i$ amb recorregut, encara que la utilització és residual, almenys entre els candidats analitzats. Es tracta del número 8, que hem descrit com selfie amb estil de youtuber que interpel.la l'usuari. Martínez Dalmau és qui més l'ha utilitzat $(n=11)$-influenciat, sense dubte, per l'ús diari d'aquest recurs que ha fet el líder nacional del seu partit, Pablo Iglesias, que ix també en els posts

Taula 6 Categoria audiovisual/Candidatura

\begin{tabular}{|c|c|c|c|c|c|c|c|}
\hline & X. Puig & I. Bonig & M. Oltra & $\begin{array}{l}\text { R. Martí- } \\
\text { nez }\end{array}$ & T. Cantó & $\begin{array}{l}\text { J. M. } \\
\text { Llanos }\end{array}$ & Total \\
\hline 3.- Tall mitjans & $32(5,5)$ & $15(2,6)$ & $57(9,8)$ & $9(1,6)$ & $82(14,2)$ & $1(0,2)$ & 196 \\
\hline 2.- Tall míting & $4(0,7)$ & $38(6,6)$ & $12(2,1)$ & $6(1,0)$ & $45(7,8)$ & $16(2,8)$ & 121 \\
\hline 6.- Espot & $35(6,0)$ & $20(3,5)$ & $20(3,5)$ & $7(1,2)$ & $23(4,0)$ & $7(1,2)$ & 112 \\
\hline 7.- Ambient & 0 & $1(0,2)$ & $17(2,9)$ & 0 & $14(2,4)$ & $27(4,7)$ & 59 \\
\hline 1.- Total & $3(0,5)$ & $18(3,1)$ & 0 & $3(0,5)$ & $16(2,8)$ & 0 & 40 \\
\hline 8.- Selfie & 0 & 0 & $7(1,2)$ & $11(1,9)$ & $5(0,9)$ & 0 & 23 \\
\hline 9.- Altres & 0 & 0 & $3(0,5)$ & $1(0,2)$ & $7(1,2)$ & $2(0,3)$ & 13 \\
\hline 5.- Emissió en directe & $6(1,0)$ & 0 & $3(0,5)$ & 0 & $1(0,2)$ & $1(0,2)$ & 11 \\
\hline 4.- Notícia inf. & $2(0,3)$ & 0 & $1(0,2)$ & $1(0,2)$ & 0 & 0 & 4 \\
\hline
\end{tabular}

$\mathrm{N}(\%)$

$X^{2}(40)=350,621^{a}, p<, 000$.

26 caselles (48,1\%) han esperat un recompte menor que 5 .

El recompte mínim esperat és $26^{a}$

Mesura simètrica nominal per nominal, Phi .778 
analitzats, ja que els ha compartit Dalmau-, seguit de Mónica Oltra $(n=7)$ i Toni Cantó ( $\mathrm{n}=$ 5). Ni Bonig ni Puig l'han utilitzat tampoc en cap moment. En qualsevol cas, cal remarcar que, més enllà del que diuen les dades de recopilació de categories, està el producte en si: recordem que l'ús d'aquests recursos pot ser contraproduent si es fa malament i no s'aconsegueix la identificació amb el receptor. Els estils dels candidats en aquestes aparicions en pantalla són totalment diferents: Martínez Dalmau es mostra titubejant i poc àgil en les seues intervencions, mentre que Cantó i Oltra demostren la seua contrastada experiència en aparicions públiques i davant de les càmeres.

Dins de la categoria 9, «Altres», destaquen dues peces que podem denominar perfils dels candidats en primera persona, però que no hem volgut incloure dins dels selfies perquè els candidats no miren a càmera, un dels trets definitoris de la categoria. Cantó, el 24 d'abril, i Dalmau, el dia següent, 25 d'abril, compartiren aquest tipus de contingut en la xarxa Twitter. Més enllà que parlen d'ells mateixos i no en termes polítics sinó personals -Cantó diu, per exemple, de l'IES Benlliure «aquí es donde estudié» i Dalmau conta el que opina de la pizza amb pinya-, el resultat final és totalment dispar: el de Cantó funciona perfectament com si fora un espot, curt i amb un missatge directe i clar; el de Dalmau, en canvi, és inexplicablement llarg i confús. Són bons exemples de la utilització diversa, i, segurament, amb efectes també molt diversos, que pot fer-se de la mateixa categoria de vídeos.

\section{CONCLUSIONS}

La primera conclusió, després d'analitzar les dades, és que entre els candidats no s'aprecia una estratègia clara en la utilització del recurs en les diverses xarxes socials. En general, no s'aprecia una sistematització regular de les estratègies de campanya entre els diferents candidats, amb un ús que és irregular i arbitrari. És evident que l'èxit en xarxes d'uns per- fils o altres no es pot construir durant la campanya, és una tasca que cal assumir abans: Trump ja era tot un influencer en Twitter abans de ser candidat a president dels Estats Units. El tràfic d'informació en les diferents xarxes depén de la popularitat prèvia: tant Oltra com Cantó, per exemple, tenen al voltant de 240.000 seguidors en Twitter. En canvi, Jose María Llanos en té tan sols 4.600. I si parlem de la diferenciació quantitativa en l'ús dels recursos audiovisuals en xarxa, així com les respectives narratives heterogènies, denota tal vegada un cert desconeixement de les capacitats persuasives dels arxius audiovisuals $i$, per tant, un desaprofitament de l'efectivitat política. Les estratègies emprades deriven d'un vídeoactivisme polític poc organitzat des del punt de vista cronològic i iconològic, en què és difícil destriar l'eficàcia entre la sobreabundància de continguts o la intermediació d'usuari a usuari. Aquestes conclusions coincideixen amb les extretes per altres estudis fets en l'àmbit espanyol, i citats en l'apartat referit a l'estat de la qüestió en la introducció.

És indiscutible, a més, la feble estratègia de comunicació audiovisual en les xarxes dels partits amb responsabilitat de govern durant les campanyes, especialment el PSPV-PSOE, enfront d'una oposició més activa i sensible a les noves xarxes i amb un target més compatible amb lelectorat jove. Aquesta investigació — circumscrita a l'àmbit de la Comunitat Valenciana - reforça la idea que un partit de la nova política, com Ciudadanos, utilitza la xarxa Twitter com el mitjà principal respecte de les altres, però no en el cas de Podemos, que en canvia l'ús segons el tipus de cita electoral, ja que en les Eleccions Generals de 2015 va ser amb diferència la força política que més va utilitzar aquesta xarxa (Miquel Segarra et al., 2017).

L'anàlisi de les dades segons l'eix esquerra/dreta mostra que els candidats de l'espectre conservador han resultat més actius compartint vídeos, especialment en Twitter, però amb una diferència poc cridanera. En relació a l'ús de la pròpia imatge, sí que trobem diferències significatives. Puig i Bonig 
assumeixen un gran protagonisme, també Oltra, però lleugerament inferior, mentre que Cantó i Martínez queden prou per baix. El cas de Llanos, que quasi no ix en els vídeos que comparteix, és poc indicatiu pel reduït ús que fa del recurs audiovisual.

Quant a la RQ2, referida a l'ús de la pròpia imatge del candidat, en la Taula 4 es mostra el percentatge d'aparició en les propostes audiovisuals implementades en les diferents xarxes socials. Tant Puig com Bonig assumeixen un gran protagonisme en els vídeos que comparteixen, ja que apareixen en més del $90 \%$ de vídeos. Oltra queda, tan sols, un poc per baix, però també amb una presència molt majoritària $(81,6 \%)$. En canvi, tant Cantó $(52,8 \%)$ com Martínez $(63,1 \%)$ queden més equilibrats, tot i que el nombre d'aparicions de Cantó és el més alt de tots els candidats, ja que la seua activitat en les xarxes és també molt més elevada. Llanos té una presència residual en el conjunt dels vídeos, una dada que, en qualsevol cas, és poc indicativa per la pobra quantitat de casos.

Cal destacar la infravaloració de l'ús d'Instagram, una xarxa consolidada en l'espai polític en campanyes internacionals on prima l'eficàcia de l'ús polític dels perfils personals durant la campanya. Recerques recents destaquen l'eficàcia d'aquesta xarxa en el màrqueting polític (Filimonov et al., 2016; Lalancette i Raynauld, 2017; Muñoz i Towner, 2017; Liebhart i Bernhardt, 2017; Quevedo Redondo i Portalés Oliva, 2017; Selva Ruiz i Caro Castaño, 2017; Langer, 2010; Driessens, 2013; Street, 2004; Van Zoonen, 2006) amb la finalitat de contribuir a la presentació pública de la persona, crear una sensació de proximitat i familiaritat amb els seguidors, aparentar certa sinceritat $\mathrm{i}$ autenticitat, i indubtablement mantenir i engrandir la base de seguidors (Marwick i Boyd, 2011). Podem concloure, doncs, que Instagram ha sigut la xarxa menys utilitzada pels candidats en general. Són Vox, Ciudadanos i Unides Podem-EUPV qui, per aquest ordre, menys l'han utilitzada. Així doncs, han perdut l'oportunitat de donar a conéixer les seues propostes programàtiques i les seues característiques personals com a dirigents polítics tant a nivell quantitatiu com qualitatiu, en la línia de les trobades d'altres investigacions (Selva Ruiz i Caro Castaño, 2017). També en altres processos electorals pròxims en el temps, com en l'intent de referèndum d'independència de Catalunya de 2017 s'ha produït un fenomen similar (Cartes Barroso, 2018).

Les narratives audiovisuals emprades per a construir un relat polític en xarxes posseeixen una clara dependència de la construcció mediàtica clàssica, especialment la televisió. Les estratègies de campanya en les últimes eleccions autonòmiques a la Comunitat Valenciana han estat desposseïdes de la construcció d'un relat propi i diferenciat en la xarxa $i$, per tant, de les enormes possibilitats que ofereix. Tots els candidats han abusat de les categories que reciclen material audiovisual procedent de mitjans tradicionals. Això sí, hi ha una diferència entre els set partits: les categories audiovisuals que hem considerat autòctones en l'univers 2.0 són, en primer lloc, la 7, «Ambient», utilitzada més profusament, en aquest ordre, per Llanos, Oltra i Cantó. Ni Puig ni Martínez han fet servir aquesta categoria. La segona tipologia que podem considerar pròpia de les xarxes, la 8, «Selfie», ha sigut més utilitzada per Martínez Dalmau, Mónica Oltra i Toni Cantó, també en aquest ordre. En aquest cas, ni Puig, ni Bonig, ni Llanos, l'han emprat. Més enllà de la quantificació, Dalmau apareix poc natural en les intervencions, fet que contrasta amb l'acusada professionalitat tant d'Oltra com de Cantó.

En qualsevol cas, la conclusió en aquest apartat és també la mateixa: l'amateurisme, l'arbitrarietat i la falta de sistematització marquen l'estratègia en xarxes de tots els candidats. En aquest estudi parcial i exploratori no entrem a valorar altres qüestions que ens semblen interessants, com la personalització i l'emocionalitat de les diferents categories audiovisuals emprades pels candidats.

No obstant això, aquesta investigació no pot extraure conclusions definitives relacionades entre els ítems «ús dels vídeos/xarxes socials» $\mathbf{i}$ «resultats electorals ", ja que hi intervenen molts altres factors que no han sigut analitzats ni eren el motiu del treball. 
Això sí, cal destacar que el PSPV-PSOE, tot i ser la quarta força política en l'ús del vídeo en xarxes socials (82 vídeos), va ser l'opció que millor resultat va obtindre -27 escons-, possiblement perquè la mateixa tasca de govern i la seua presència en els mitjans de comunicació i en les xarxes socials durant 4 anys de gestió política són un aparador de promoció política potent. En aquesta línia argumentativa, cal dir el contrari de la força Compromís. Tot i ser part del Govern del Botànic, la seua estratègia en l'ús de vídeos, que els col-loca com la segona força en la utilització d'aquest recurs amb 120 peces, no va evitar la pèrdua de confiança en les urnes amb dos escons menys (de 19 el 2015 a 17 el 2019). El contrari li va passar a Toni Cantó (primer del rànquing amb 193 vídeos) i la seua estrena com a cap de llista de Ciu- dadanos, ja que en les eleccions de 2015 el seu partit tragué 13 escons i ara s'ha situat, amb 18 escons, com la tercera força política de les Corts Valencianes i, com a conseqüència, ha desplaçat Compromís a la quarta posició (17 escons). Per últim, cal reflectir la irrupció de Vox, una força nova que, a pesar de ser la penúltima en utilitzar el vídeo i fer-ho únicament a través de Twitter (52 peces) i de forma residual en Facebook ( 2 peces), ha aconseguit un resultat històric de 10 escons amb el suport de 278.000 vots.

Considerem, per tant, que estudis posteriors poden estendre l'anàlisi a altres convocatòries electorals i altres candidats, fet que contribuiria a enriquir la visió de conjunt i particularitzar més les relacions entre ús de xarxes socials/vídeos i resultats electorals.

REFERÈNCIES BIBLIOGRÀFIQUES

Alcat, E. (2011). Influye!: Claves para dominar el arte de la persuasión. Madrid: Alienta Editorial. DOI: 10.22478/ ufpb.1809-4783.2018v28n3.42534

Arias Maldonado, M. (2016). La digitalización de la conversación pública: Redes sociales, afectividad política y democracia. Revista de Estudios Políticos, 173, 27-54. DOI: 10.18042/cepc/rep.173.01.

Barberá González, R. i Cuesta Cambra, U. (2018). Información política y redes sociales en Estados Unidos: De Obama a Trump. Informação \& Sociedade, 28(3). DOI: 10.22478/ufpb.1809-4783.2018v28n3.42534

Baviera, T., García Ull, F. i Cano Orón, L. (2017). Twitter: ¿protagonismo vicario? En G. López García i L. Valera Ordaz (coor.), Pantallas electorales: El discurso de partidos, medios y ciudadanos en la campaña de 2015. Barcelona: Editorial UOC.

Benkler, Y., Faris, R. i Roberts, H. (2018). Network propaganda. Nova York: Oxford University Press.

Bennett, W. L. (2012). The Personalization of Politics: Political Identity, Social Media, and Changing Patterns of Participation. The Annals of the American Academy of Political and Social Science, 644(1), 2039. DOI: $10.1177 / 0002716212451428$

Bernal, A. I. (2015). Tecnología, redes sociales, política y periodismo. ¿pluralidad informativa o efecto bumerán? Cuadernos.info, (36), 191-205. doi:10.7764/cdi.36.647

Caldevilla Dominguez, D. (2009). Democracia 2.0: La política se introduce en las redes sociales. Pensar la Publicidad. Revista Internacional de Investigaciones Publicitarias, $12(2), 31$.

Campos Domínguez, E. i Calvo, D. (2017). La campaña electoral en Internet: Planificación, repercusión y viralización en Twitter durante las elecciones españolas de 2015. Comunicación y Sociedad, 29, 93-116. DOI: https://doi.org/ $10.32870 /$ cys.v0i29.6423

Cartes Barroso, M. J. (2018). El uso de Instagram por los partidos políticos catalanes durante el referéndum del 1/O; Revista de Comunicación de la SEECI, 17. DOI: 10.15198/seeci.2018.0.17-36

Castells, M. (2001). La Galaxia Internet. Barcelona: Plaza \& Janés.

Cocker, H. L. i Cronin, J. (2017). Charismatic Authority and the YouTuber: Unpacking the New Cults of Personality. Marketing Theory, 17(4), 455-472. DOI: 10.1177/1470593117692022 
Crilley, R. i Gillespie, M. (2019). What to Do about Social Media? Politics, Populism and Journalism. Journalism, 20(1), 173-176. DOI: $10.1177 / 1464884918807344$

Dader García, J. L. i Campos, E. (2006). Internet parlamentario en España (1999-2005). Zer: Revista de estudios de comunicación, 20. Recuperat de http://dialnet.unirioja.es/servlet/oaiart?codigo=2238674

DelMoral,J.A.(2006).Losprincipiosdela política 2.0. Recuperatdehttps://blogs.alianzo.com/redessociales/2006/02/21/ los-principios-de-la-politica-2-0/

Dent, S. (2017). Food Dominates Facebook Video Views, Study Shows. Recuperat de https://bit.ly/31R31rN

Doyle, G. (2015). Multi-platform Media and the Miracle of the Loaves and Fishes. Journal of Media Business Studies, 12(1), 49-65. DOI: 10.1080/16522354.2015.1027113

Driessens, O. (2013). The Celebritization of Society and Culture: Understanding the Structural Dynamics of Celebrity Culture. International Journal of Cultural Studies, 16(6), 641-657. DOI: 10.1177/1367877912459140

Eco, U. (1968). Apocalípticos e integrados. Madrid: Lumen.

Elorriaga Illera, A. i Monge Benito, S. (2018). La profesionalización de los youtubers: El caso de Verdeliss y las marcas. Revista Latina de Comunicacion Social, 2018 (73), 37-54. DOI: 10.4185/RLCS-2018-1244

Filimonov, K., Russmann, U. i Svensson, J. (2016). Picturing the Party: Instagram and Party Campaigning in the 2014 Swedish Elections. Social Media + Society, 2(3), 1-11. DOI: 10.1177/2056305116662179

Guterres Ludwig, F. A. (2009). La campaña online de Barack Obama en 2008. Cuadernos de H Ideas, 3. Recuperat de http://dialnet.unirioja.es/servlet/oaiart?codigo $=4650000$

Habermas, J. (1989). The Public Sphere. En Steven Seidman (ed.), Jürgen Habermas on Society and Politics: A reader (p. 231-236). Boston: Beacon Press.

IAB (Interactive Advertising Bureau), (2018). Estudio anual de redes sociales 2018. Recuperat de https://iabspain.es/ investigacion

Jenkins, H. (2006). Convergence Culture: Where Old and New Media Collide. Nova York: NYU Press. Recuperat de https://www.jstor.org/stable/j.ctt9qffwr

Jenkins, H. (2017). How Young Activists Use Social Media for Social Change: A Transnational Perspective. Recuperat de http://henryjenkins.org/blog/2017/9/26/how-young-activists-use-social-media-for-social-change-atransnational-perspective

Kompare, D. (maig 2002). Flow To Files: Conceiving 21st Century Media. Ponència presentada en Media In Transition 2 , Cambridge, MA. Resum recuperat de: https://cmsw.mit.edu/mit2/Abstracts/DerekKompare.pdf

Lago Vázquez, D., Direito Rebollal, S., Rodríguez Vázquez, A. i López García, X. (2016). El consumo millennial de información política en televisión y redes sociales: Análisis de la campaña Elecciones Generales en España 2015. Revista Latina de Comunicacion Social, 71, 1.151-1.169. DOI: 10.4185/RLCS-2016-1139

Lalancette, M. i Raynauld, V. (2017). The Power of Political Image: Justin Trudeau, Instagram, and Celebrity Politics. American Behavioral Scientist, 63(7), 888-924. DOI: 10.1177/0002764217744838

Langer, A. I. (2010). The Politicization of Private Persona: Exceptional Leaders or the New Rule? The Case of the United Kingdom and the Blair Effect. The International Journal of Press/Politics, 15(1), 60-76. DOI: $10.1177 / 1940161209351003$

Larsson, A. O. (2017). Skiing All the Way to the Polls. Convergence: The International Journal of Research into New Media Technologies. DOI: 10.1177/1354856517741132

Larsson, A. O. (2018). The News User on Social Media. Journalism Studies, 19(15), 2.225-2.242. DOI: $10.1080 / 1461670 X .2017 .1332957$

Liebhart, K. i Bernhardt, P. (2017). Political Storytelling on Instagram: Key Aspects of Alexander Van der Bellen's Successful 2016 Presidential Election Campaign. Media and Communication, 5(4), 15. DOI: 10.17645/mac. v5i4.1062

Livingstone, S. M. (2009). Children and the Internet. Cambridge: Polity. Recuperat de https://bit.ly/2WUHE51

Loader, B. D. i Mercea, D. (2011). Networking Democracy?: Social Media Innovations and Participatory Politics. Information, Communication \& Society, 14(6), 757-769. DOI: 10.1080/1369118X.2011.592648

López García, G. (2016). "Nuevos” y “viejos" liderazgos: La campaña de las elecciones generales españolas de 2015 en Twitter. Comunicación y Sociedad, 29(3) 149-167. DOI: 10.15581/003.29.3 
López Olano, C. i Fenoll, V. (2020). La polarización mediática en el proceso de independencia en Cataluña: Estudio comparativo del tratamiento en RT. Mediterranean Journal of Communication, 11(1), 261-272. DOI: 10.14198/ MEDCOM2020.11.1.22

López Rabadán, P. i Doménech Fabregat, H. (2018). Instagram y la espectacularización de las crisis políticas: Las 5W de la imagen digital en el proceso independentista de Cataluña. El Profesional de la Información, 27(5), 1013-1029. DOI: 10.3145/epi.2018.sep.06

May, A. L. (2010). Who Tube? How YouTube's News and Politics Space is going Mainstream. The International Journal of Press/Politics, 15(4), 499-511. DOI: 10.1177/1940161210382861

Marwick, A. i Boyd, D. (2011). To See and Be Seen: Celebrity Practice on Twitter. Convergence: The International Journal of Research into New Media Technologies, 17(2), 139-158. DOI: 10.1177/1354856510394539

Miquel Segarra, S., Alonso Muñoz. L.i Marcos García, S. (2017). Buscando la interacción: Partidos y candidatos en Twitter durante las elecciones generales de 2015. Prisma Social, 18, 34-54. Recuperat de http://revistaprismasocial.es/ article/view/1353

Muñoz, C. L. i Towner, T. L. (2017). The Image is the Message: Instagram Marketing and the 2016 Presidential Primary Season. Journal of Political Marketing, 16(3-4), 290-318. DOI: 10.1080/15377857.2017.1334254

Pariser, E. (2011). The Filter Bubble. Londres: Viking.

Pérez Torres, V., Pastor Ruiz, Y. i Abarrou Ben Boubaker S. (2018). Los youtubers y la construcción de la identidad adolescente. Comunicar, 26(55), 61-70. DOI: 10.3916/C55-2018-06

Prado, E. (2013). La televisió: un univers en mutació. L'Espill, 43, 129-150.

Quevedo Redondo, R. i Portalés Oliva, M. (2017). Imagen y comunicación política en Instagram: Celebrificación de los candidatos a la presidencia del gobierno. El Profesional de la Información, 26(5), 916-927. DOI: 10.3145/ epi.2017.sep.13

Raby, R., Caron, C., Théwissen LeBlanc, S., Prioletta, J. i Mitchell, C. (2018). Vlogging on YouTube: The Online, Political Engagement of Young Canadians Advocating for Social Change. Journal of Youth Studies, 21(4), 495-512. DOI: $10.1080 / 13676261.2017 .1394995$

Sampietro, A i Sánchez Castillo, S. (2020). La promoción de la imagen política en Instagram: Un estudio del perfil personal de Santiago Abascal (Vox) en 2018. Communication \& Society, 33(1), 169-184. DOI: 10.15581/ 003.33.1.169-184

Scolari, C. A. i Fraticelli, D. (2017). The Case of the Top Spanish YouTubers: Emerging Media Subjects and Discourse Practices in the New Media Ecology. Convergence. DOI: 10.1177/1354856517721807

Selva Ruiz, D. i Caro Castaño, L. (2017). Uso de Instagram como medio de comunicación política por parte de los diputados españoles: La estrategia de humanización en la "vieja" y la "nueva" política. El Profesional de la Información, 26(5), 903. DOI: 10.3145/epi.2017.sep.12

Storsul, T. (2014). Deliberation or Self-presentation?: Young People, Politics and Social Media. Nordicom Review, 35(2), 17-28. DOI: 10.2478/nor-2014-0012

Street, J. (2004). Celebrity Politicians: Popular Culture and Political Representation. The British Journal of Politics and International Relations, 6(4), 435-452. DOI: 10.1111/j.1467-856X.2004.00149.x

Trump, D. i Zanker, B. (2008). Think Big and Kick Ass in Business and Life. Nova York: Collins.

Túñez, M. i Sixto, J. (2011). Redes sociales, política y compromiso 2.0: La comunicación de los diputados españoles en Facebook. Revista Latina de Comunicación Social, 66, 210-234. Recuperat de https://bit.ly/2ZD410I

Valera, L., Sampietro, A. i Fenoll, V. (2017). El debate ciudadano en redes sociales: ¿Libertad o intimidación?. Pantallas electorales. El discurso de partidos, medios y ciudadanos en la campaña de 2015. Barcelona: Editorial UOC.

Van Zoonen, L. (2006). The Personal, the Political and the Popular. European Journal of Cultural Studies, 9(3), 287-301. DOI: $10.1177 / 1367549406066074$ 


\section{NOTA BIOGRÀFICA}

\section{Carlos López Olano}

Llicenciat en Filologia Hispànica (Literatura Espanyola) i Comunicació Audiovisual, així com doctor en Comunicació. Actualment és professor del departament de Teoria dels Llenguatges de la Universitat de València. Ha sigut investigador i professor visitant a universitats com les de Roehampton i Glasgow o la Hebrew University of Jerusalem. Ha treballat en diversos mitjans audiovisuals com ara Atresmedia, RTVV o À Punt Mèdia i investiga sobre el futur de la televisió pública, les tecnologies mutliplataforma i transmèdia i la memòria.

\section{Sebastián Sánchez Castillo}

Doctor en Comunicació Audiovisual (2008) i professor titular de Comunicació Audiovisual a la Universitat de València. Les seues investigacions se centren en l'anàlisi dels efectes dels mitjans i, en particular, la teoria dels mitjans d'entreteniment, la persuasió narrativa, l'anàlisi dels efectes sociocognitius dels marcs de notícies (Framing) i la comunicació de la salut (malalties rares o minoritàries). A través de la seua col·laboració científica amb el grup d'investigació Mediaflows de la Universitat de València — «Flujos de comunicación en los procesos de movilización política», CSO2016-77331-C2-1-R (2017-2020)—, ha abordat estudis sobre comunicació electoral, mitjans de comunicació i formació de l'opinió pública, els fluxos de circulació dels missatges en els processos de comunicació política i l'impacte de les noves tecnologies en la formació de corrents d'opinió.

\section{Benjamín Marín Pérez}

Llicenciat en Periodisme per la Universitat Politècnica de València (CEU S. Pablo, 1991) i doctor en Periodisme per la Universitat Complutense de Madrid (2000). Té un Màster Executive en Direcció d'Empreses i Màrqueting (EMBA) per l'ESIC (2015) i un Màster Universitari en Comunicació Social de la Investigació Científica per la Universidad Internacional de Valencia (2018). És professor associat des de 2003 del Departament de Teoria dels Llenguatges i Ciències de la Comunicació de la Universitat de València. Ha sigut professor de comunicació de postgrau a la Universitat de València; de màrqueting i comunicació de grau i postgrau a l'ESIC i de postgrau a la Universidad Internacional de Valencia i CEU Cardenal Herrera. És també director de Comunicació i Màrqueting a À Punt Mèdia. La seua línia d'investigació se centra en la televisió, la comunicació política i la comunicació digital externa i interna de les empreses i organitzacions. 